\title{
Study On Dynamics Characteristics And Damping Measures About Backrest Adjuster's Transmission Parts Based on ADAMS
}

\author{
Yu Bao-jun ${ }^{1, a}$, Tian Peng ${ }^{2, b}$,Lin Jie-qiong ${ }^{3, c^{*}}$, Xin Tian-tian $^{4, d}$ \\ Changchun University of Technology, China

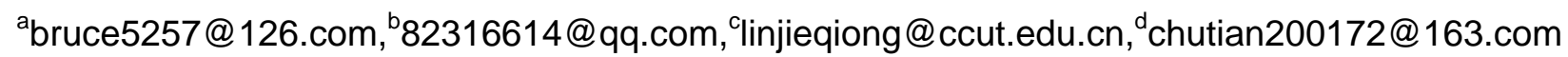

Keywords: CATIA; ADAMS; Backrest adjuster's transmission parts; Dynamic simulation; Vibration reduction component

\begin{abstract}
Create three-dimensional model of backrest adjuster's transmission parts by using CATIA, and then, the model was imported into the dynamic simulation software ADAMS. based on multi-body system dynamics theory and the ADAMS, dynamics research and analysis are carried out for backrest adjuster's transmission parts. System modes and frequency response-magnitude was studied in different conditions of amplitude. The vibration reduction component before and after adding the two cases by force and acceleration data tested. Through the comparison verified the feasibility of the method. The results are going to provide a theoretical basis for the design, manufacture and forced vibration of backrest adjuster's transmission parts.
\end{abstract}

\section{Introduction}

With the development of auto industry, auto electric chair has been widely used, backrest adjuster is an important component of the electric car seat, backrest adjuster is the main load bearing parts between seat backrest and the base, and backrest adjuster's quality of the performance is of great significance to the safety of the car seat. Electric seat adjustment backrest angle is done by motor, motor drive shaft turn it produces vibration, thus the core parts of illustrates causes impact and noise in the process of transmission. The vibration will occur components deformation and damage. To solve this problem, the approach is to add vibration in shaft parts, in this paper we verify the 3d model simulation based on the virtual instrument on ADAMS. For the establishment of the backrest adjuster dynamic simulation models and analyze system mode, we will create three-dimensional of backrest adjuster in CATIA model and then the model is input in ADAMS software and the mechanical virtual principle prototype is modeled in ADAMS, To provide more reliable data for 3D model, we compare and analysis simulation results by different conditions through the created model tested by the movement simulation in practical work. This step of Virtual prototype is set up by use of ADAMS software is shown in Figure 1. 


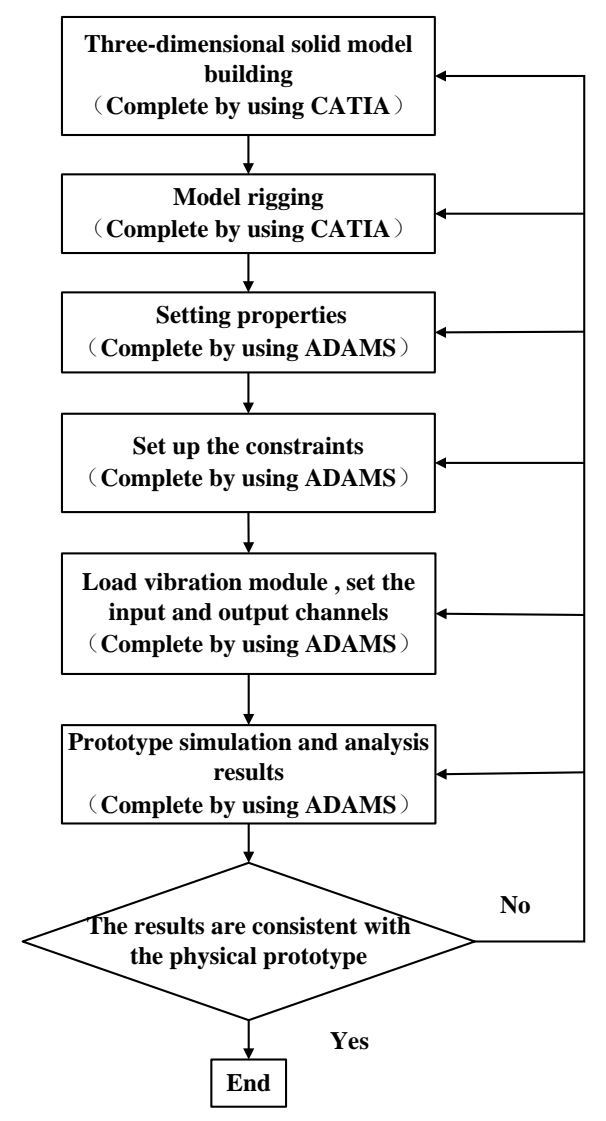

Figure1 simulation steps

\section{Three-dimensional Solid Modeling and Data Conversion}

Establish Three-dimensional Solid Model.Since the solid modeling functions provided by Adams is not suitable for building complex 3d surface, so the solid modeling's establishment of the backrest adjuster by using CATIA software. In the Windows environment, CATIA 3D modeling software for the graphics platform, establishing the three-dimensional solid model of backrest and taking advantage of part CATIA in the assembly module to establish a good solid model assembled together, Figure 2 is backrest adjuster model.

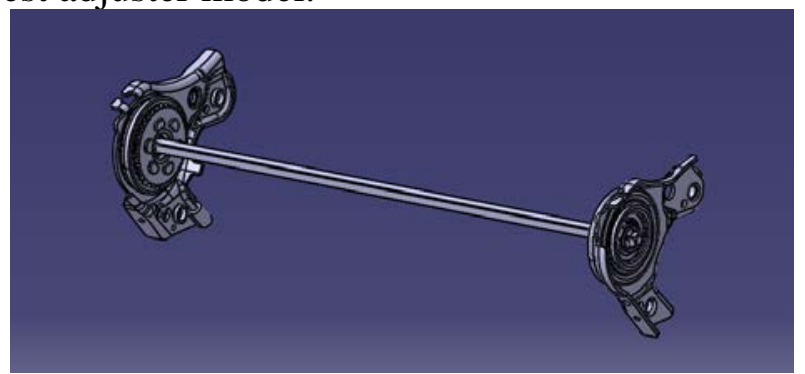

Figure 2 backrest adjuster model

The Data Conversion and the Establishment of Dynamic Model. Assembling the three-dimensional solid model in CATIA, the model is converted into file format approved Adams and then imported into Adams.

\section{Build Dynamics Analysis Model}

It sets requisite constraints, physical attributes, vibration exciter, and defines collision force between objects for the built model in the ADAMS.

Choice of Force. There are two kinds of contact force models in Adams, namely Recovery Coefficient Model and Shock Function Model. Recovery Coefficient Model is based on impulse theory. It is adaptive to use this model if accurate materials recovery coefficient can be get but 
stiffness and damping coefficient are unknown. It can be also used in the discontinuous-type contact. As it is based on impulse law, velocity field is discontinuous. So, the acceleration cannot be completely specified, so is the contact force. Therefore, Recovery Coefficient Model is unsuitable to be used if accurate contact force is needed or collision velocity has little effect on contact behavior (continuous contact question). Shock Function Model defines contact force with displacement and speed. It can be used in continuous contact and discontinuous contact. Stiffness is related to material properties and its physical significance is obvious. When the stiffness is too big and causes convergence difficult, it can adjust penetration depth to improve convergence. This calculation method is relatively stable. Therefore, it is reasonable to apply Shock Function Model to calculate contact force. Summarily, Shock Function Model, namely Impact Function, is used to calculate contact force in this paper.

Calculation method of IMPACT:

$$
\operatorname{MAX}\left\{0, K\left(q_{0}-q\right)^{e}-c \times \frac{d q}{d t} \times \operatorname{STEP}\left(q, q_{0}-d, 1, q_{0}, 0\right)\right\}
$$

Here, $q$ is the actual distance between two objects, $d q / d t$ is speed, $q_{0}$ is the reference distance between two nearly contact objects, $k$ is stiffness, $e$ is rigid power index, $c$ is damping rate, $d$ is the distance when damping rate arrives the peak. When $q_{0}-q \leq 0$, Impact Function is invalid and the members do not collide with each other. When $q_{0}-q \geq 0$, collision will be happen.

Setting Vibrator Module. It analyses frequency domain of forced response in different test points of model used the ADAMS/Vibration module. Firstly, it transfers ADAMS linearized model to vibration module, sets incoming and outgoing channels for vibration analysis, and defines frequency domain incoming function to get scientific modal information.

\section{Frequency Response Function and Dynamics Simulation}

Frequency Response Function. First derive single degree of freedom frequency response function expression, Figure 3 is a common single degree of freedom model.

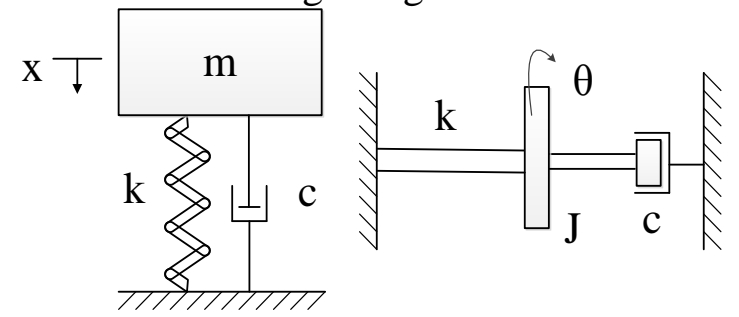

Figure 3 single degree of freedom model

The single degree of freedom system refers to with a generalized coordinates can describe its motion vibration system. For a single degree of freedom vibration system its quality is $\mathrm{m}$, spring constant $k$, the damping coefficient is c, In a time-varying external force $f(t)$ effect, the mass vibrates in the vicinity of the equilibrium position, and at time $t$ equals $t$, displacement of mass deviation from the equilibrium position is $x(t)$, the kinetic equation of single degree of freedom system can be written as:

$$
m \ddot{x}(t)+c \dot{x}(t)+k x(t)=f(t)
$$

Rearranging this equation:

$$
\ddot{x}(t)+2 \zeta \omega_{0} \dot{x}(t)+\omega_{0}^{2} x(t)=\frac{f(t)}{m}
$$

Fourier transform on both sides of the equation:

$$
\left(\omega_{0}^{2} \pm \omega^{2}+2 j \zeta \omega_{0} \omega\right) X(\omega)=\frac{F(\omega)}{m}
$$

Displacement $\mathrm{x}(\mathrm{t})$ and the force $\mathrm{f}(\mathrm{t})$ of the Fourier transform: 


$$
\begin{aligned}
& X(\omega)=\int_{-\infty}^{\infty} x(t) e^{-j \omega t} d t \\
& F(\omega)=\int_{-\infty}^{\infty} f(t) e^{-j \omega t} d t
\end{aligned}
$$

The equation (4) can be rewritten as $X(\omega)=H_{d}(\omega) F(\omega)$

$$
H_{d}(\omega)=\frac{1}{m\left(\omega_{0}^{2} \pm \omega^{2}+2 j \zeta \omega_{0} \omega\right)}
$$

The equation (7) for the single degree of freedom of the displacement frequency response function, it describes the relationship between the displacement response in the frequency domain $\mathrm{w}$ single degree of freedom system and exciting force. The equations (7) twice derivation in the frequency domain can be drawn acceleration frequency response function, Thus the relationship between acceleration frequency response function and displacement frequency response function as follows:

$$
H_{a}(\omega)=-\omega^{2} H_{d}(\omega)=\frac{-\omega^{2}}{m\left(\omega_{0}^{2} \pm \omega^{2}+2 j \zeta \omega_{0} \omega\right)}
$$

But in the actual many of the structures can not be reduced to a single degree of freedom system, most structural features emerged more degrees of freedom. Therefore many-degrees of freedom system is universal. Many-degrees of freedom system dynamic equations can be written as:

$$
[m] \ddot{x}(t)+[c] \dot{x}(t)+[K] x(t)=\{f(t)\}
$$

$[m],[c]$ and $[K]$, respectively for the mass matrix, damping matrix and stiffness matrix in the equations (9), fourier transform on both sides of the equation(9):

$$
\{x(\omega)\}=[H(\omega)]\{F(\omega)\}
$$

When the many-degrees of freedom system has proportional damping, the frequency response function expressed as:

$H_{i j}(\omega)$ of expression element in the $[H(\omega)]$.

$$
[H(\omega)]=\sum_{r=1}^{n} \frac{\left\{\varphi_{r}\right\}\left\{\varphi_{r}\right\}^{T}}{k_{r}-\omega^{2} m_{r}+j \omega c_{r}}
$$

$$
H_{i j}(\omega)=\sum_{r=1}^{n} \frac{\varphi_{i r} \varphi_{j r}}{k_{r}-\omega^{2} m_{r}+j \omega C_{r}}
$$

The equation for the system frequency response function between the $\mathrm{i}, \mathrm{j}$ two points, $m_{r}$, $k_{r}$ and $c_{r}$, respectively for the mode mass, mode stiffness and mode damping coefficient of the mode number $r$ in the equations, $\left\{\varphi_{r}\right\}$ is modal lineup vector of the mode number $r$.

Simulation Result. Figure 4 and 5 are the modal information, the frequency response curve respectively, which is obtained under the conditions of simulation time $t=1 \mathrm{~s}$, steps $=100$, the maximum amplitude of the vibrator is 1 . 
FREQUENCY UNITS: $(\mathrm{Hz})$

\begin{tabular}{|c|c|c|c|c|c|}
\hline MODE & UNDAMPED NATURAL & DAMPING & & & \\
\hline NUMBER & FREQUENCY & RATIO & REAL & & IMAGINARY \\
\hline 1 & $7.187737 \mathrm{E}-004$ & $1.000000 \mathrm{E}+000$ & $7.187737 \mathrm{E}-004$ & & $0.000000 \mathrm{E}+000$ \\
\hline 2 & $7.187783 \mathrm{E}-004$ & $1.000000 \mathrm{E}+000$ & $-7.187783 \mathrm{E}-004$ & & $0.000000 \mathrm{E}+000$ \\
\hline 3 & $1.426207 \mathrm{E}-001$ & $1.000000 \mathrm{E}+000$ & $1.426207 \mathrm{E}-001$ & & $0.000000 \mathrm{E}+000$ \\
\hline 4 & $1.426207 \mathrm{E}-001$ & $1.000000 \mathrm{E}+000$ & $-1.426207 \mathrm{E}-001$ & & $0.000000 \mathrm{E}+000$ \\
\hline 5 & $3.665242 \mathrm{E}+000$ & $1.000000 \mathrm{E}+000$ & $3.665242 \mathrm{E}+000$ & & $0.000000 \mathrm{E}+000$ \\
\hline 6 & $3.665258 \mathrm{E}+000$ & $1.000000 \mathrm{E}+000$ & $-3.665258 \mathrm{E}+000$ & & $0.000000 \mathrm{E}+000$ \\
\hline 7 & $6.685888 \mathrm{E}+002$ & $1.000000 \mathrm{E}+000$ & $6.685888 \mathrm{E}+002$ & & $0.000000 \mathrm{E}+000$ \\
\hline 8 & $6.686193 \mathrm{E}+002$ & $1.000000 \mathrm{E}+000$ & $-6.686193 \mathrm{E}+002$ & & $0.000000 \mathrm{E}+000$ \\
\hline 9 & $1.359383 \mathrm{E}-003$ & $5.526677 \mathrm{E}-006$ & $7.512874 \mathrm{E}-009$ & $+1-$ & $1.359383 \mathrm{E}-003$ \\
\hline 10 & $3.831213 \mathrm{E}-003$ & $5.139957 \mathrm{E}-006$ & $-1.969227 \mathrm{E}-008$ & $+1-$ & $3.831213 \mathrm{E}-003$ \\
\hline 11 & 1. $851793 \mathrm{E}-002$ & $8.921787 \mathrm{E}-001$ & $1.652131 \mathrm{E}-002$ & $+1-$ & $8.364228 \mathrm{E}-003$ \\
\hline 12 & $1.851804 \mathrm{E}-002$ & $8.921731 \mathrm{E}-001$ & $-1.652129 \mathrm{E}-002$ & $+/-$ & $8.364478 \mathrm{E}-003$ \\
\hline 13 & $3.235812 \mathrm{E}-002$ & $2.971837 \mathrm{E}-001$ & $9.616306 \mathrm{E}-003$ & $+1-$ & $3.089619 \mathrm{E}-002$ \\
\hline 14 & $3.235813 \mathrm{E}-002$ & $2.971834 \mathrm{E}-001$ & $-9.616298 \mathrm{E}-003$ & $+1-$ & $3.089620 \mathrm{E}-002$ \\
\hline 15 & $5.407321 \mathrm{E}-002$ & $6.405845 \mathrm{E}-001$ & $3.463846 \mathrm{E}-002$ & $+1-$ & $4.152215 \mathrm{E}-002$ \\
\hline 16 & $5.407321 \mathrm{E}-002$ & $6.405844 \mathrm{E}-001$ & $-3.463846 \mathrm{E}-002$ & $+1-$ & $4.152215 \mathrm{E}-002$ \\
\hline 17 & $1.622679 \mathrm{E}+000$ & $5.750139 \mathrm{E}-007$ & $9.330630 \mathrm{E}-007$ & $+1-$ & $1.622679 \mathrm{E}+000$ \\
\hline 18 & $7.485445 \mathrm{E}+000$ & $9.174855 \mathrm{E}-007$ & $-6.867787 \mathrm{E}-006$ & $+1-$ & $7.485445 \mathrm{E}+000$ \\
\hline 19 & $8.304416 \mathrm{E}+000$ & $2.238240 \mathrm{E}-006$ & $1.858728 \mathrm{E}-005$ & $+1-$ & $8.304416 \mathrm{E}+000$ \\
\hline 20 & 1. $495187 \mathrm{E}+001$ & $5.377152 \mathrm{E}-006$ & $-8.039849 \mathrm{E}-005$ & $+1-$ & $1.495187 \mathrm{E}+001$ \\
\hline
\end{tabular}

Figure 4 modal information

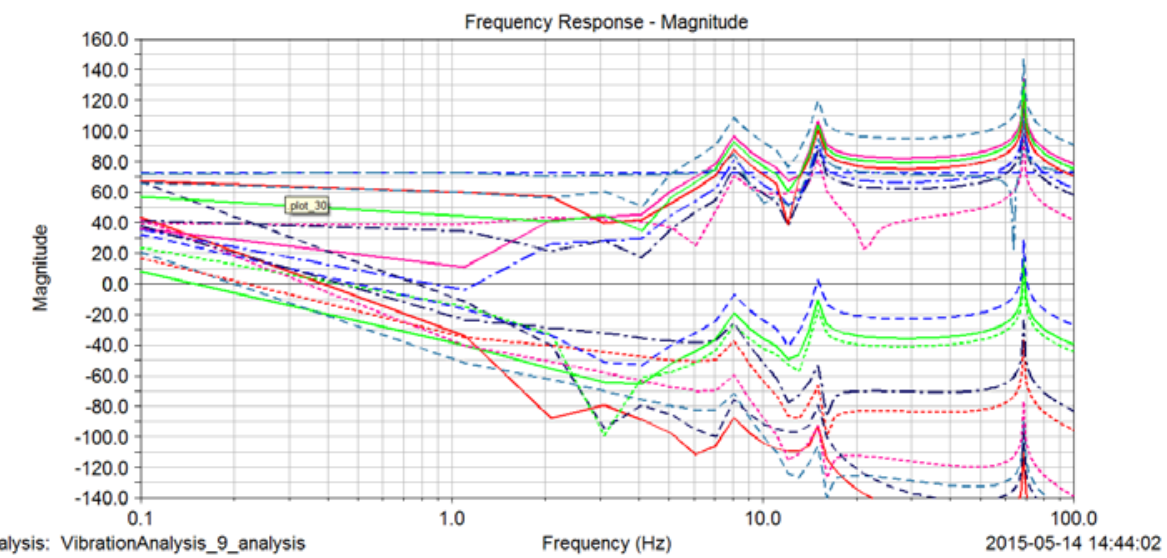

Figure 5 frequency response curve

Figure 6 and 7 are the modal information, the frequency response curve respectively, which is obtained under the conditions of simulation time $t=1 \mathrm{~s}$, steps $=100$, the maximum amplitude of the vibrator is 2 .

\begin{tabular}{|c|c|c|c|c|c|}
\hline \multicolumn{6}{|c|}{ EIGEN VALUES (Time $=0.0)$} \\
\hline MODE & UNDAMPED NATURAL & DAMPING & & & \\
\hline NUMBER & FREQUENCY & RATIO & REAL & & IMAGINARY \\
\hline 1 & $7.187737 \mathrm{E}-004$ & $1.000000 \mathrm{E}+000$ & $7.187737 \mathrm{E}-004$ & & $0.000000 E+000$ \\
\hline 2 & $7.187783 \mathrm{E}-004$ & $1.000000 \mathrm{E}+000$ & $-7.187783 \mathrm{E}-004$ & & $0.000000 \mathrm{E}+000$ \\
\hline 3 & $1.426207 \mathrm{E}-001$ & $1.000000 \mathrm{E}+000$ & $1.426207 \mathrm{E}-001$ & & $0.000000 \mathrm{E}+000$ \\
\hline 4 & $1.426207 \mathrm{E}-001$ & $1.000000 \mathrm{E}+000$ & $-1.426207 \mathrm{E}-001$ & & $0.000000 \mathrm{E}+000$ \\
\hline 5 & $3.665242 \mathrm{E}+000$ & $1.000000 \mathrm{E}+000$ & $3.665242 \mathrm{E}+000$ & & $0.000000 \mathrm{E}+000$ \\
\hline 6 & $3.665258 \mathrm{E}+000$ & $1.000000 \mathrm{E}+000$ & $-3.665258 \mathrm{E}+000$ & & $0.000000 \mathrm{E}+000$ \\
\hline 7 & $6.685888 \mathrm{E}+002$ & $1.000000 \mathrm{E}+000$ & $6.685888 \mathrm{E}+002$ & & $0.000000 \mathrm{E}+000$ \\
\hline 8 & $6.686193 \mathrm{E}+002$ & $1.000000 \mathrm{E}+000$ & $-6.686193 E+002$ & & $0.000000 \mathrm{E}+000$ \\
\hline 9 & $1.359383 \mathrm{E}-003$ & $5.526677 \mathrm{E}-006$ & $7.512874 \mathrm{E}-009$ & $+1-$ & $1.359383 \mathrm{E}-003$ \\
\hline 10 & $3.831213 \mathrm{E}-003$ & $5.139957 \mathrm{E}-006$ & $-1.969227 \mathrm{E}-008$ & $+1-$ & $3.831213 \mathrm{E}-003$ \\
\hline 11 & $1.851793 \mathrm{E}-002$ & $8.921787 \mathrm{E}-001$ & $1.652131 \mathrm{E}-002$ & $+1-$ & $8.364228 \mathrm{E}-003$ \\
\hline 12 & $1.851804 \mathrm{E}-002$ & $8.921731 \mathrm{E}-001$ & $-1.652129 \mathrm{E}-002$ & $+1-$ & $8.364478 \mathrm{E}-003$ \\
\hline 13 & $3.235812 \mathrm{E}-002$ & $2.971837 \mathrm{E}-001$ & $9.616306 \mathrm{E}-003$ & $+/-$ & $3.089619 \mathrm{E}-002$ \\
\hline 14 & $3.235813 \mathrm{E}-002$ & $2.971834 \mathrm{E}-001$ & $-9.616298 \mathrm{E}-003$ & $+1-$ & $3.089620 \mathrm{E}-002$ \\
\hline 15 & $5.407321 \mathrm{E}-002$ & $6.405845 \mathrm{E}-001$ & $3.463846 \mathrm{E}-002$ & $+1-$ & $4.152215 \mathrm{E}-002$ \\
\hline 16 & $5.407321 \mathrm{E}-002$ & $6.405844 \mathrm{E}-001$ & $-3.463846 \mathrm{E}-002$ & $+1-$ & $4.152215 \mathrm{E}-002$ \\
\hline 17 & $1.622679 \mathrm{E}+000$ & $5.750139 \mathrm{E}-007$ & $9.330630 \mathrm{E}-007$ & $+1-$ & $1.622679 \mathrm{E}+000$ \\
\hline 18 & $7.485445 E+000$ & $9.174855 \mathrm{E}-007$ & $-6.867787 E-006$ & $+1-$ & $7.485445 \mathrm{E}+000$ \\
\hline 19 & $8.304416 \mathrm{E}+000$ & $2.238240 \mathrm{E}-006$ & $1.858728 \mathrm{E}-005$ & $+1-$ & $8.304416 \mathrm{E}+000$ \\
\hline 20 & $1.495187 \mathrm{E}+001$ & $5.377152 \mathrm{E}-006$ & $-8.039849 \mathrm{E}-005$ & $+1-$ & $1.495187 \mathrm{E}+001$ \\
\hline 21 & 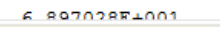 & 1 1 $\triangle G 7 R R \triangle F-\cap \cap \triangle A$ & 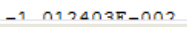 & $+1-$ & 6 207กวRT=0ก1 \\
\hline
\end{tabular}

Figure 6 modal information 


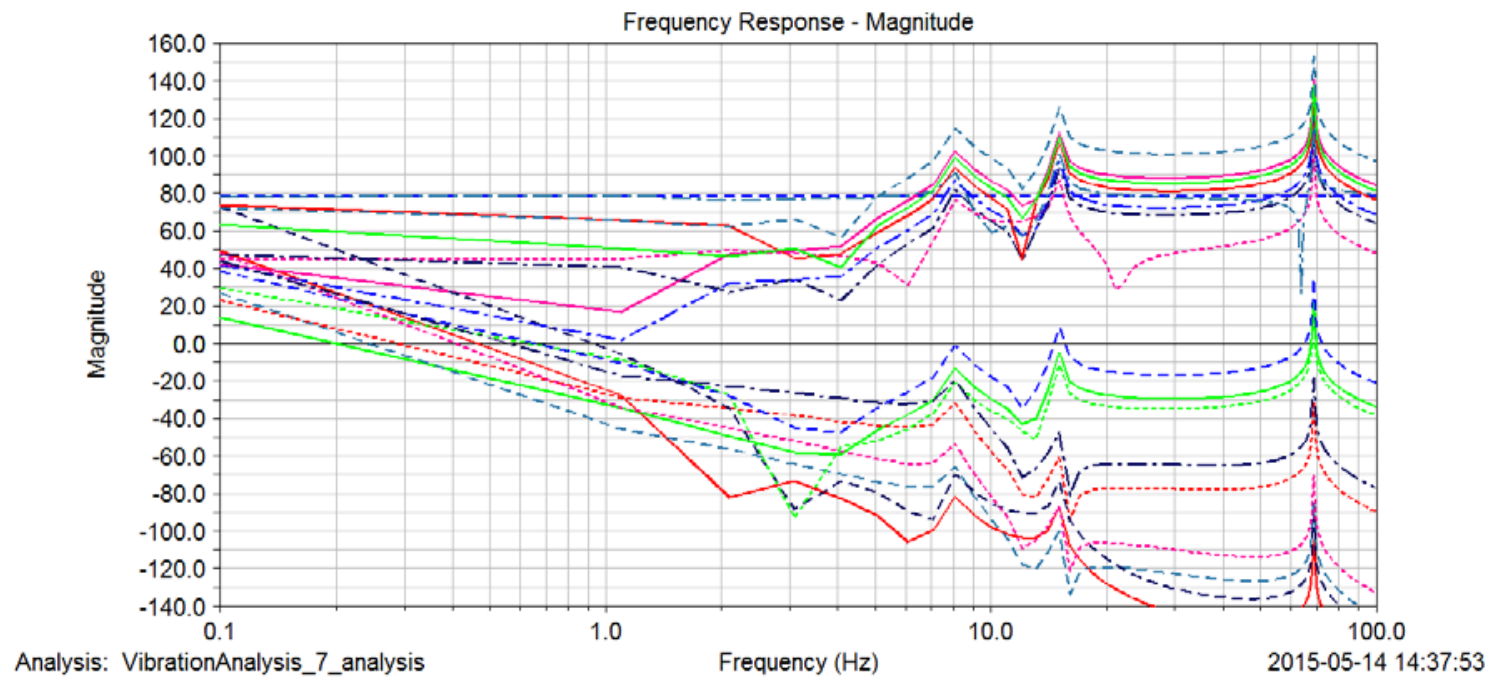

Figure 7 frequency response curve

By the above simulation results and the frequency response function can be seen, the equations (12) show that has nothing to do with the amplitude frequency response function, so the simulation result is correct. And undamped natural frequency depends on the real part when the damping ratio is 1 , the result is in conformity with the theory of undamped natural frequency only depends on the mass and stiffness. So can draw dynamic simulation software ADAMS can accurately simulate the backrest adjuster, this provides a basis for further analysis dynamic characteristics and structure improvement of the adjuster by using Adams.

\section{Research on Vibration Reduction Measures}

The main source of vibration in the transmission process of electric seat transmission components is the drive shaft, drive shaft vibration is due to the motor rotate, so we can reduce the transmission shaft vibration to further reduce the vibration of the transmission parts. Method used in this paper is to add two fixed component on the seat, each member has a round hole, can make the shaft through it and the shaft are in interference fit, these two components respectively placed on both sides of the motor and near the two end backrest adjuster, such as figure 8 .

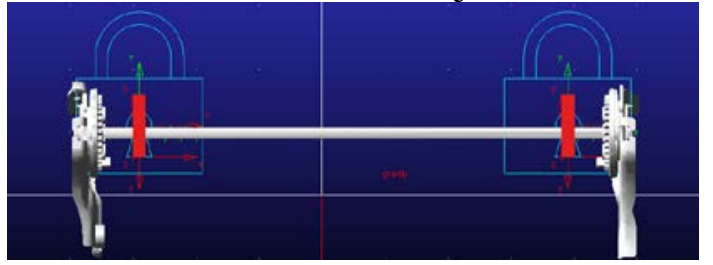

Figure 8 the scheme of two fixed component

Good elastic material on the surface of component round hole can be very good absorb the vibration of transmission shaft, also can be reduce the shock and noise in the process of vibration between damping and shaft component.

In this paper, the vibration reduction component before and after adding the two cases by force and acceleration data tested. Through the comparison verified the feasibility of the method. Respective simulation test on two cases after loading the vibration .

Without adding the damping component set $t=1 \mathrm{~s}$, steps $=100$ for simulation, such as figure 9 to figure 12 are the test results caused by the vibration at the two ends backrest adjuster's force, displacement, velocity and acceleration. 

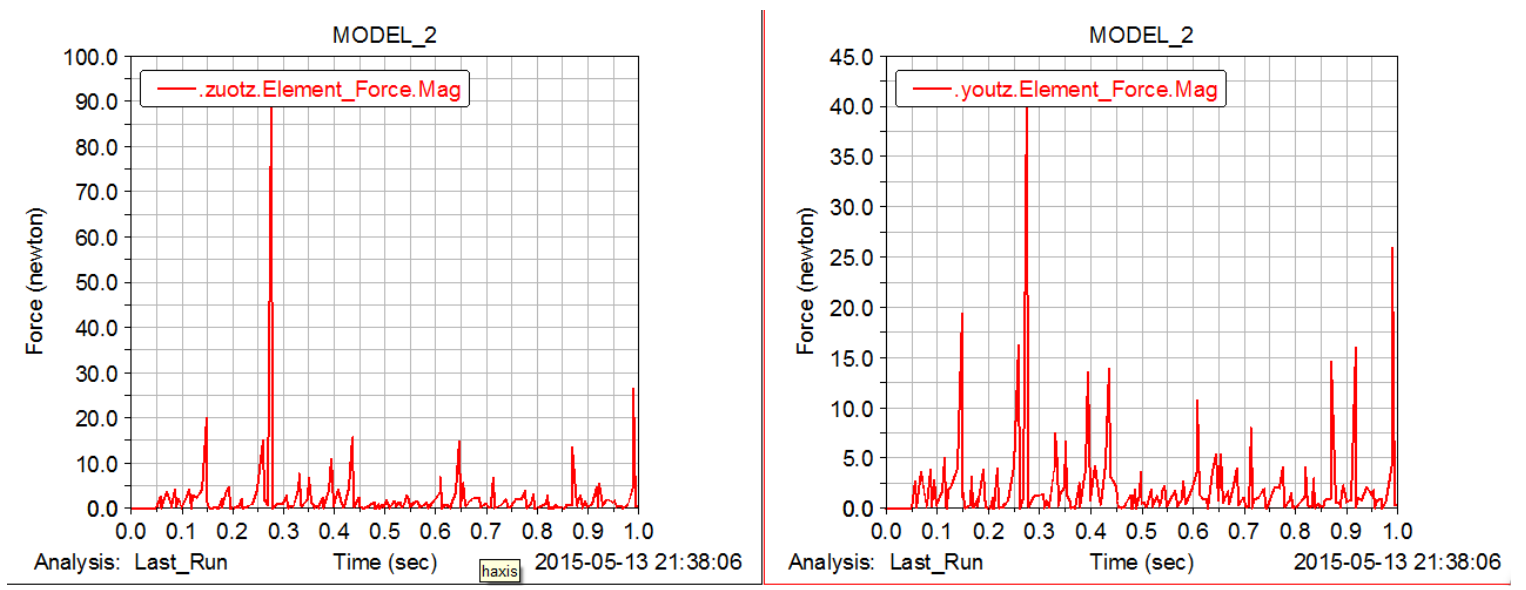

Figure 9 the test results caused by the vibration at the two ends backrest adjuster's force (without adding the damping component)

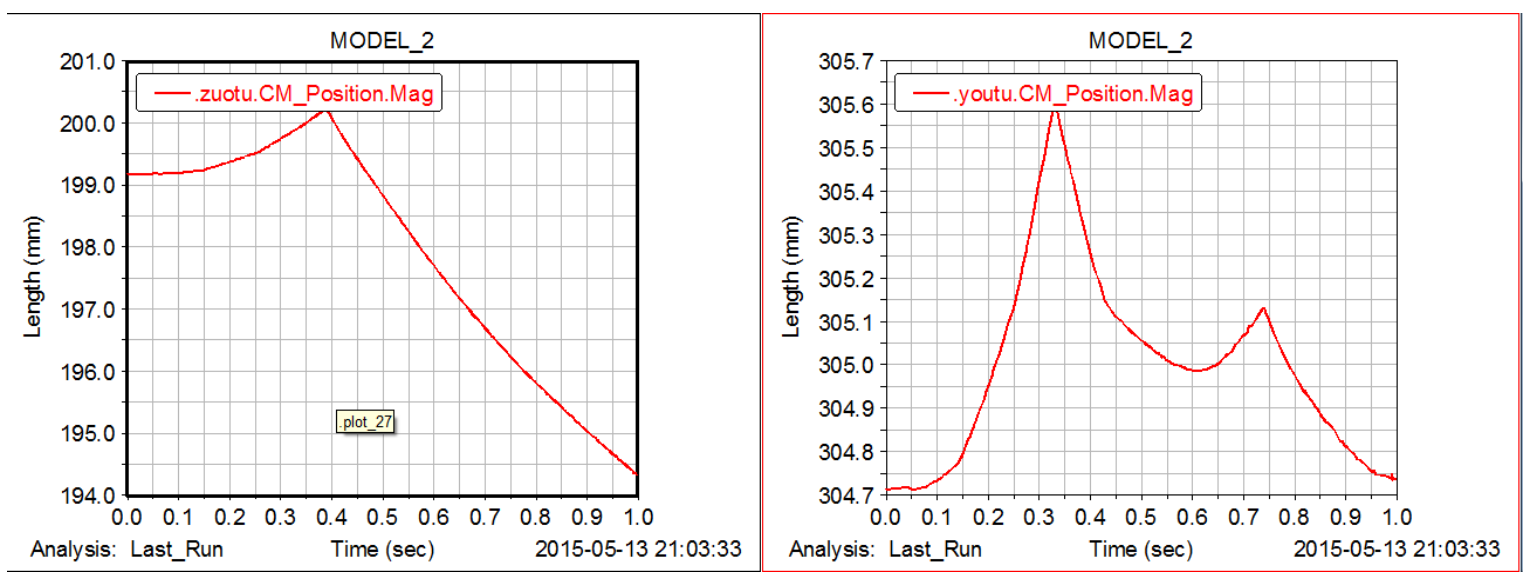

Figure 10 the test results caused by the vibration at the two ends backrest adjuster displacement (without adding the damping component)
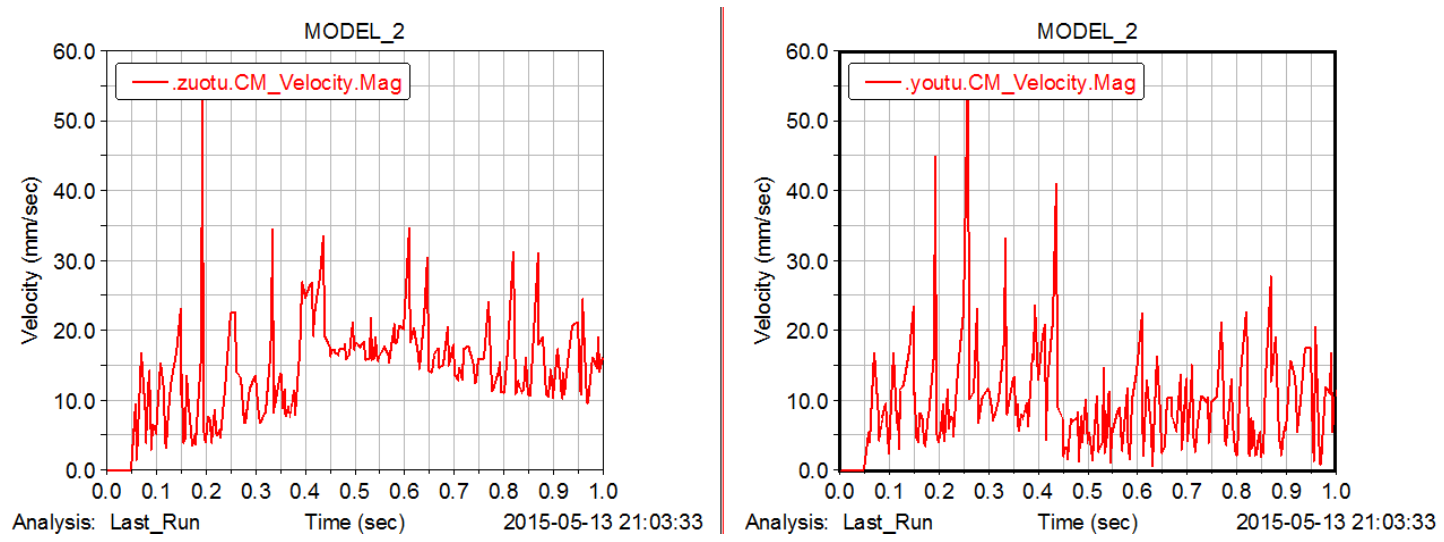

Figure 11 the test results caused by the vibration at the two ends backrest adjuster velocity (without adding the damping component) 

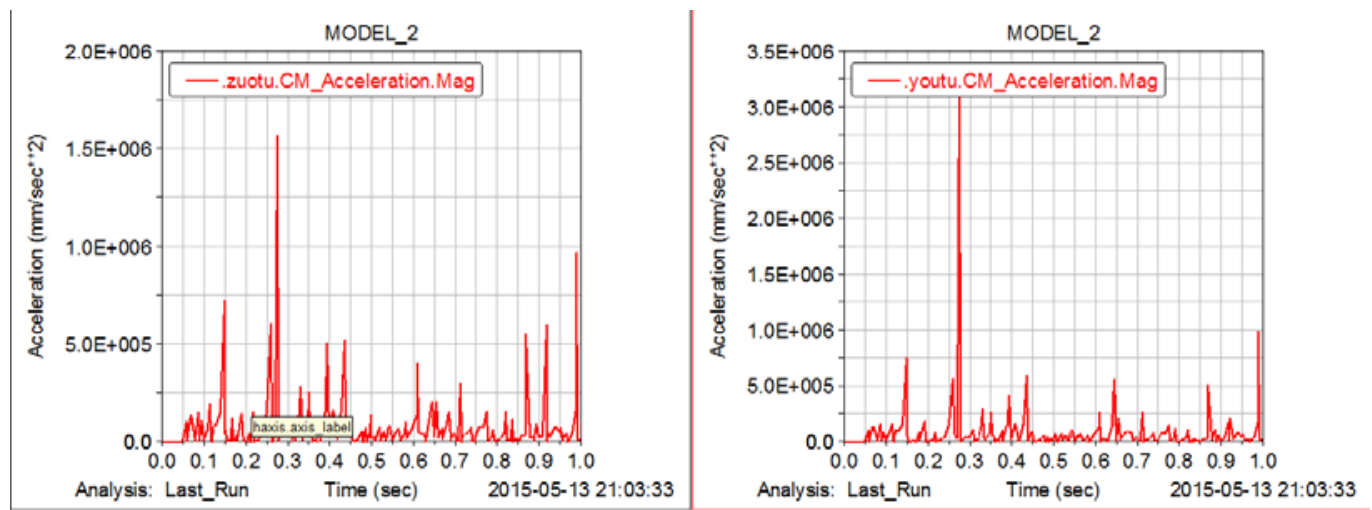

Figure 12 the test results caused by the vibration at the two ends backrest adjuster acceleration (without adding the damping component)

In the case of adding damping component set $t=1 \mathrm{~s}$, steps $=100$ for simulation, such as figure 13 to 16 are the test results caused by the vibration at the two ends of the backrest adjuster of the force, displacement, velocity and acceleration.
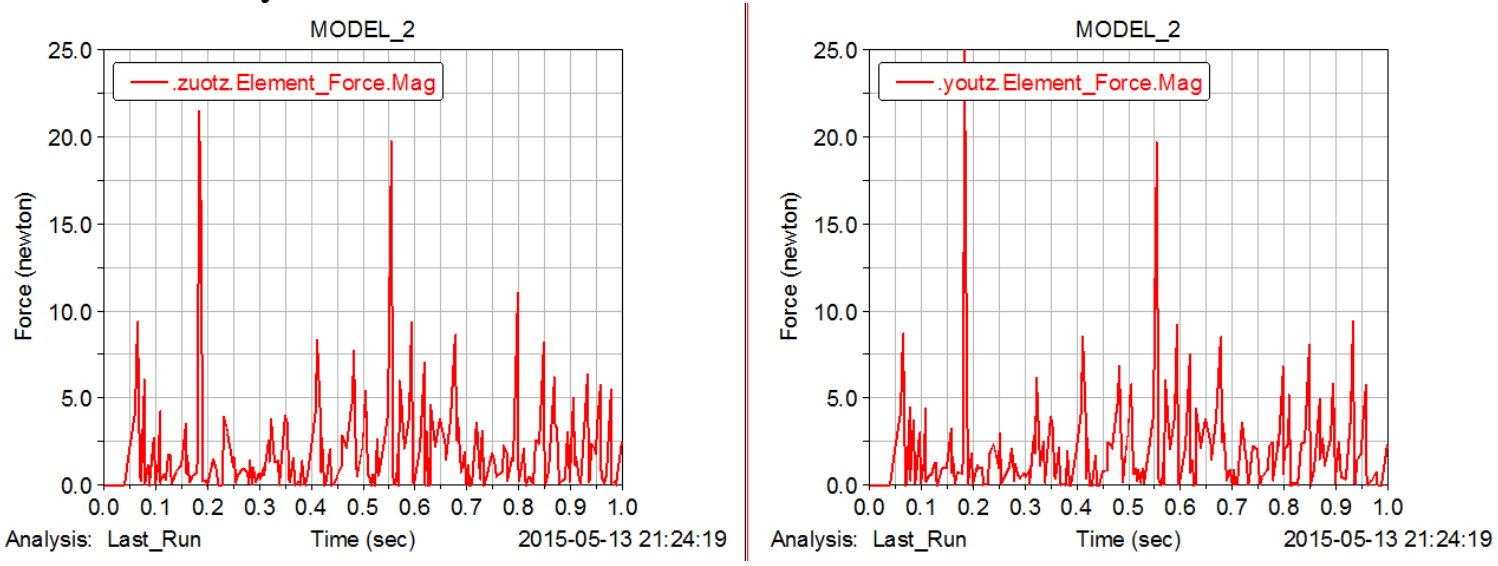

Figure 13 the test results caused by the vibration at the two ends of the backrest adjuster of the force (adding damping component)
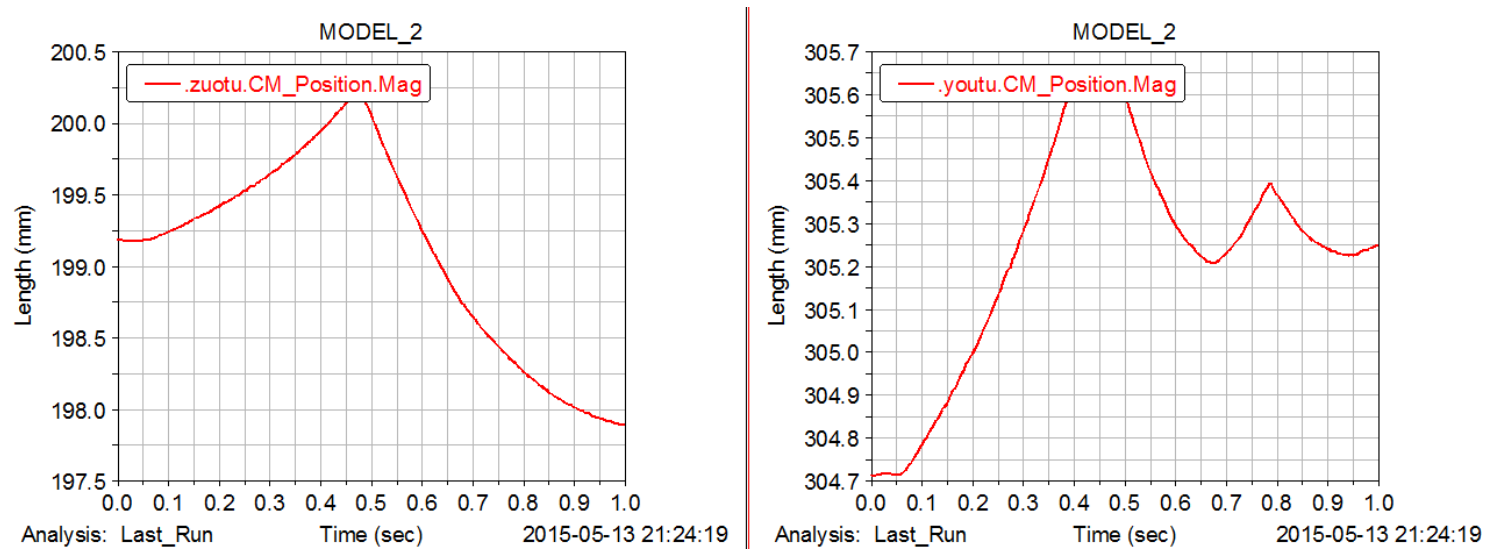

Figure 14 the test results caused by the vibration at the two ends of the backrest adjuster of the displacement (adding damping component) 

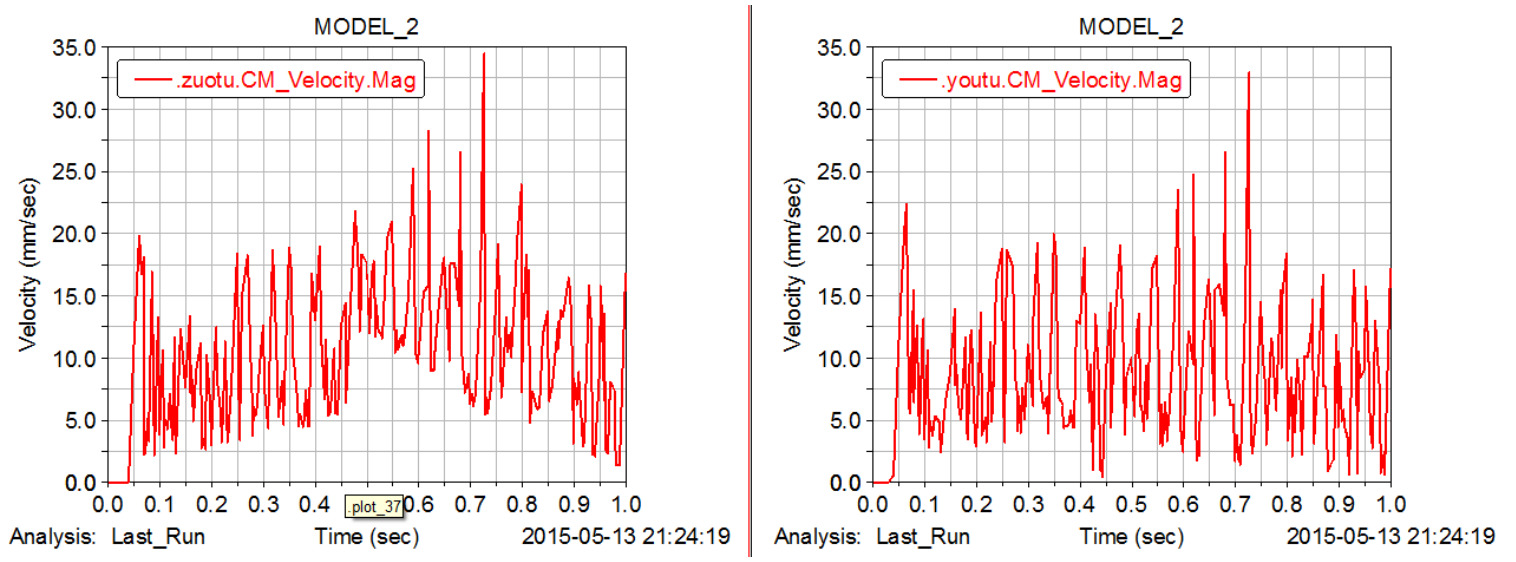

Figure 15 the test results caused by the vibration at the two ends of the backrest adjuster of the velocity (adding damping component)

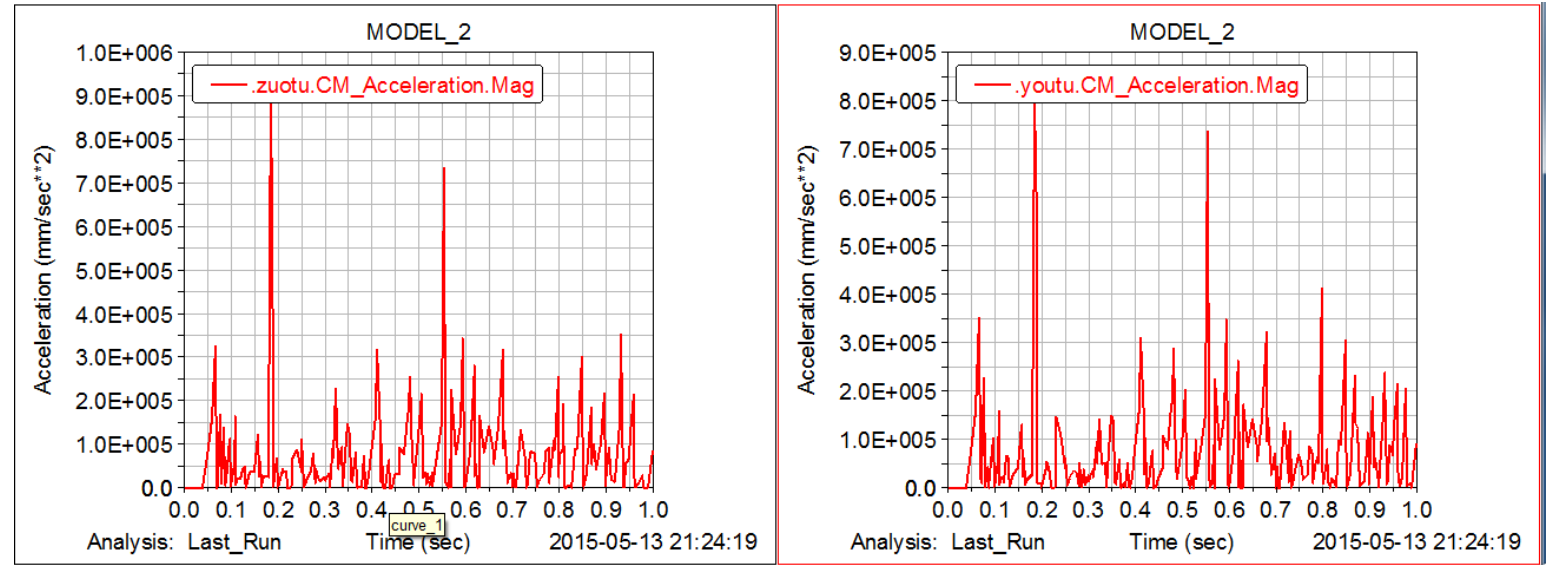

Figure 16 the test results caused by the vibration at the two ends of the backrest adjuster of the acceleration (adding damping component)

From the above results, the results show that after adding the damping component, the backrest adjuster, velocity and acceleration have significantly reduce caused by vibration , the displacement is small after the changes of adding a damping component, verified the damping mechanism can effectively reduce vibration of transmission components of the backrest adjuster, so as to ease the impact backrest adjuster between components, and will not affect the transfer of the motion.

\section{Conclusion}

In Adams environment, establishing backrest adjuster transmission system's virtual prototyping of dynamic characteristics, and obtaining experimental data. The results show that the simulation model is effective by using ADAMS, it can truly simulate the working process of the system, so take it as a basis for the research of vibration reduction measures, this paper verifies the feasibility of the added damping parts by using ADAMS, By comparing some parameters, it proved that the damping components can effectively reduce the vibration of the driving part, such as the adjuster's stress and acceleration of added damping parts before and after. the method of dynamic characteristics in the course of the study, the computer simulation studies of the backrest adjuster, help backrest adjuster theory in simulation to further improvement and development, will be has a positive meaning with the backrest adjuster design and develop.

\section{Acknowledgements}

This paper is supported by the Jilin science and technology development project (project number: 20130305002GX) and Changchun science and technology project (project number:13KG15). 


\section{References}

[1].Chen Fenghua.2013.ADAMS2013 Virtual prototype technology from entry to the master[M].Tsinghua University Press.

[2]. Li Jinyu \& Gou Zhijian\&Li Yuan.2005.A dynamic simulation of meshing force in gear meshing process based on ADAMS[J]. Machine Design and Research.

[3]. Yang Zhen.2002.Impact load simulation theory [D].Xi`an Jiaotong University.

[4]. Pei Weichi \& Li Yaogang \& Li Yunhong. 2008.Based on virtual prototype technology- ADAMS impact model[J]. North China University of Science and Technology.

[5]. Wang Hongbo \& Ma Shiping \& Wang Honggang. 2007.Study on dynamics characteristics and fatigue analysis about gear transmission based on ADAMS [J].Machine Tool \& Hydraulics.

[6].K.L.Johnson.1985.Contact Mechanics[M]. Combridge University Press.

[7]. Tan Xin \& Yin Ming.2013.Mechanical engineering control foundation[M]. Publishing House of Electronics Industry. 